\title{
MONITORAMENTO DA QUALIDADE DA ÁGUA NO CÓRREGO CHUMBEADINHA - OURINHOS/SP
}

\author{
Ernesto Vendramini Bergamaschi ${ }^{1}$
}

Rodrigo Lilla Manzione ${ }^{2}$

Natalia Felix Negreiros ${ }^{3}$

\begin{abstract}
RESUMO: A água é um recurso vital para a existência de todos os organismos vivos, e a captação para uso doméstico, produção agrícola, mineração, produção industrial, geração de energia, atividades de lazer e práticas florestais podem levar à deterioração da sua qualidade, atingindo o ecossistema aquático e também a disponibilidade de água potável disponível para consumo humano. O presente trabalho teve como objetivo monitorar a qualidade da água do Córrego Chumbeadinha no município de Ourinhos-SP, que perpassa pela área urbana da cidade e é desprovido de mata ciliar em quase todo seu percurso, além de sofrer dois represamentos artificiais. O Córrego Chumbeadinha é um afluente de segunda ordem do Rio Paranapanema, percorrendo cerca $4 \mathrm{~km}$ de sua nascente até sua foz. Foram realizadas amostragens das seguintes variáveis: Sólidos em Suspensão, $\mathrm{pH}$, concentração de oxigênio dissolvido, condutividade elétrica, temperatura da água, coliformes fecais, transparência da água, além do cálculo do índice de estado trófico, em quatro locais no curso do córrego, de setembro de 2009 a abril de 2010. Dessa forma, o córrego Chumbeadinha nasce com uma qualidade boa, apesar de sofrer forte pressão da expansão urbana, porém os demais pontos foram classificados como eutróficos, sendo registrada a presença de coliformes fecais em todas as amostragens. A falta de vegetação nas margens do lago pode ser a grande causadora da

\footnotetext{
${ }^{1}$ Geógrafo.UNESP - Campus de Ourinhos. evbernesto@hotmail.com

${ }^{2}$ Engenheiro agrônomo, Docente - UNESP Mestre em agronomia - UNESP/FCA. Doutor em sensoriamento remoto - INPE. manzione@ourinhos.unesp.br

${ }^{3}$ Bióloga, Docente - UniSalesiano, Araçatuba-SP. Mestre em Ecologia e Recursos Naturais e Doutoranda em Ciências no Programa de Pós-Graduação em Ecologia e Recursos Naturais, Universidade Federal de São Carlos. natalia felix@yahoo.com.br.
} 
eutrofização, pois os sedimentos não encontram dificuldades para chegar até o curso d'água, assim interferindo diretamente no IET do lago.

Palavras-chave: Limnologia, Eutrofização, Monitoramento.

\section{INTRODUÇÃO}

A água é um recurso vital para a existência de todos os organismos vivos. Atualmente está cada vez mais ameaçada à medida que as populações humanas crescem e exigem-a de melhor qualidade para uso doméstico e/ou atividades econômicas. A captação de água para uso doméstico, produção agrícola, mineração, produção industrial, geração de energia, atividades de lazer e práticas florestais podem levar à deterioração da sua qualidade. Este impacto não atinge apenas o ecossistema aquático, mas também a disponibilidade para o consumo humano.

Os ambientes aquáticos são matrizes complexas que requerem o uso cuidadoso para garantir o funcionamento sustentável destes ecossistemas no futuro. Assim, a gestão destes requer uma compreensão dos vínculos importantes entre as propriedades dos ecossistemas e de que maneira as atividades humanas podem alterar a interação entre os processos químicos, físicos e biológicos.

Segundo a UNEP (2006) a qualidade da água não é uma condição estática de um sistema, nem pode ser definido pela medição de apenas um parâmetro. Pelo contrário, é variável no tempo e no espaço e exige um acompanhamento de rotina para detectar padrões espaciais e mudanças ao longo do tempo.

O monitoramento regular de suas propriedades físicas, químicas e biológicas pode servir para se evitar situações extremas, na qual a capacidade de um ecossistema para retornar ao seu estado natural após ser alterado (degradado) é quase impossível, orientando sempre medidas mitigadoras e de controle para que o mesmo possa voltar o mais próximo possível ao seu estado natural.

Há uma variedade de agentes físicos, químicos e biológicos e componentes que afetam a qualidade da água, além de centenas de variáveis que podem ser examinadas e avaliadas.

Segundo Moraes (2001) a poluição térmica pode vir na forma de impactos diretos, 


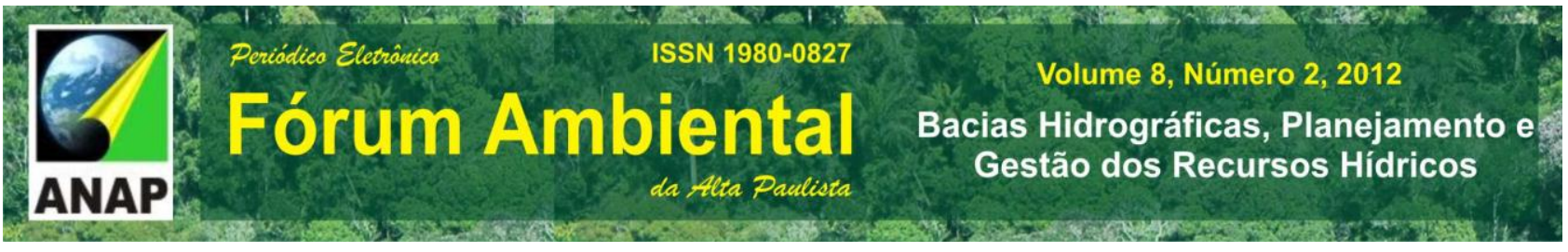

como a descarga de água de refrigeração industrial ou indiretamente por meio de atividades humanas tais como a remoção da vegetação na margem do córrego ou a construção de represamentos. Em condições extremas pode causar a mortalidade de seres aquáticos, e pode ainda influenciar a solubilidade do oxigênio dissolvido (OD) e de outros materiais dissolvidos na coluna de água, afetando a velocidade das reações químicas, a taxa fotossintética, o metabolismo de outros organismos, a influência dos poluentes, parasitas e outros agentes patogênicos que interagem com os habitantes aquáticos (Sipaúba-Tavares, 1994).

Para Moraes (2001) a condutividade elétrica pode detectar fontes poluidoras, uma vez que valores elevados podem indicar poluição, constituindo uma maneira de avaliar a disponibilidade de nutrientes nos sistemas aquáticos. Segundo este mesmo autor, a influência do $\mathrm{pH}$ pode-se dar direta e indiretamente, afetando a atividade biológica, e contribuindo na precipitação de elementos químicos tóxicos como metais, além de outras condições que podem exercer efeitos sobre a solubilidade de nutrientes. Dentre os gases dissolvidos na água, o oxigênio é um dos mais importantes na dinâmica e caracterização dos ecossistemas aquáticos, sendo indispensável à quase totalidade das funções vitais.

A fonte de sedimentos no corpo hídrico inclui atividades naturais e antrópicas, como a erosão natural do solo ou excessiva por parte da agricultura, pecuária, silvicultura, escoamento de construções urbanas, efluentes industriais ou o crescimento de fitoplâncton em excesso favorecendo o assoreamento dos mesmos, o que pode afetar a navegabilidade do rio bem como os recursos bióticos e abióticos.

Para avaliar as consequências da poluição sobre os ecossistemas aquáticos continentais são necessários vários tipos de informações. O registro de organismos bioindicadores aliados aos parâmetros físico-químicos constitui uma ótima ferramenta para detectar o nível de comprometimento da vida aquática e avaliar o nível de degradação ambiental (Callisto et al., 2005). Os coliformes totais, fecais e estreptococos fecais podem ser utilizados como indicadores de poluição fecal na água (Colwell, 1978).

O fornecimento de água potável e acessível para pessoas ao redor do mundo, além da promoção do uso sustentável dos recursos hídricos são os objetivos fundamentais da ONU, no programa Desenvolvimento do Milênio. Com isso, tanto o monitoramento da qualidade quanto da quantidade da água na superfície do solo e dos 
recursos hídricos é uma atividade necessária em todos os níveis que regem: local, nacional e internacional.

O presente estudo teve como principal objetivo fazer o diagnóstico da qualidade das águas do Córrego Chumbeadinha, localizado no município de Ourinhos-SP. Esse córrego nasce dentro da área urbana, e cerca de 500 metros à jusante sofre dois represamentos, formando lagos artificiais que contribuem para o paisagismo da cidade e recreação da população, com a prática de pesca.

\section{MATERIAIS E MÉTODOS}

\section{Área de Estudo}

O córrego Chumbeadinha (Figura 1A) é um córrego de $2^{a}$ ordem, de acordo com a classificação de Strahler (1957) e situa-se na porção oeste da cidade de Ourinhos-SP, com sua nascente nas coordenadas 2258'14.30" S e 4953'12.14". O córrego sofre o primeiro represamento a 400 metros da nascente e o segundo logo depois, até ser escoado por três ladrões para que possa seguir seu curso até o rio Paranapanema. Da nascente a foz, o córrego tem aproximadamente $4,1 \mathrm{Km}$ de extensão, perpassando $1 / 4$ dentro do perímetro urbanizado, sofrendo com a degradação ambiental causada pelo não gerenciamento adequado dos corpos hídricos urbanos. A área de estudo (Figura 1B) foi dividida em quatro pontos amostrais, de setembro de 2009 a abril de 2010, pois representam diferentes características de ocupação: Nascente, Represamento 1, Represamento 2 e na saída do Ladrão principal do Represamento 2. A nascente sofre com a quase inexistência de mata ciliar, uma fábrica de tijolos a 50 metros. No entanto, os lagos sofrem as maiores influências externas, pois dentro da micro bacia localizam-se 3 postos de combustíveis, podendo ocorrer a contaminação do lençol freático ou até mesmo por vazamentos de derivados do petróleo, além de receber as águas das lavagens dos carros com materiais químicos. Existem ainda outras fontes potencialmente poluidoras: lançamento de esgoto doméstico no lago 1. Próximo ao lago 2 existe um loteamento, onde o solo desprovido de vegetação facilita o transporte de sedimentos para dentro do lago, promovendo o processo de assoreamento. 

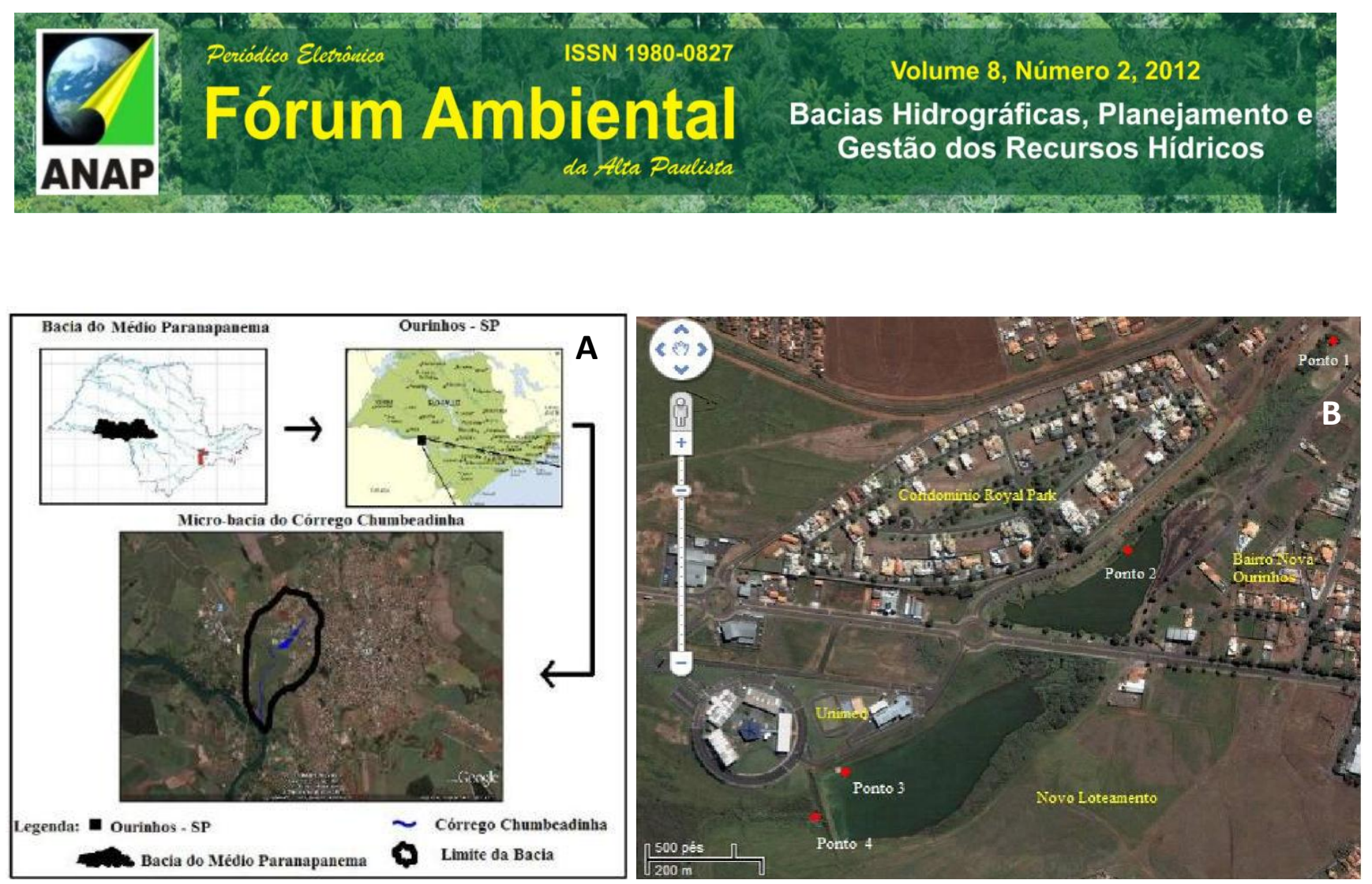

Figura 1. A - Localização do córrego Chumbeadinha na Bacia do Médio Paranapanema, no estado de São Paulo. B - Pontos de coleta e principais empreendimentos próximos ao Córrego Chumbeadinha, Ourinhos/SP.

(Fonte: Google Earth - adaptado).

\section{Variáveis abióticas}

A temperatura da água foi mensurada aparelho digital da marca Windaus, modelo Temperaturme $\beta$ gerät, a condutividade elétrica, $\mathrm{pH}$ e concentração de oxigênio dissolvido foram aferidos por um condutivímetro - MARTE, modelo MB - 11p, pHmetro - CRISON, modelo $\mathrm{PH} 25$ e um oxímetro digital - CRISON, modelo OXI45. A transparência da água foi determinada através da realização de leituras do desaparecimento e reaparecimento visual do disco de Secchi. Para calcular o limite da zona eufótica o valor da transparência da água foi multiplicado pelo coeficiente empírico igual a 2,7 (MARGALEF, 1983).

Para a coluna d'água de cada localidade foi calculado o Índice de Estado Trófico (IET) de Carlson, modificado por Toledo et al. (1983), considerando-se a visibilidade do disco de Secchi. A análise dos sólidos em suspensão na água foram realizadas com um Cone de Imnhoff, segundo metodologia descrita em APHA (1998). 
A vazão da nascente foi calculada pelo método de vazão por capacidade, segundo Tucci (2007) expressos em litros/segundo.

Os valores apresentados referentes a precipitação, foram retirados dos pontos de controle da estação meteorológica do INPE, localizados no lago da Unimed e no Aeroporto, gentilmente cedidos pelo laboratório de Climatologia da UNESP - Campus Experimental de Ourinhos.

\section{Variável biológica}

Análises de coliformes fecais foi realizado um teste para detecção de Coliformes Totais e E.coli da marca COLItest ${ }^{\circledR}$, com resultado de presença e ausência.

\section{RESULTADOS E DISCUSSÃO}

O monitoramento sistemático das águas do Córrego Chumbeadinha caracterizou a variabilidade temporal dos parâmetros de qualidade da água em função das variações sazonais. Foram realizadas 21 visitas a campo, e na tabela 1 estão apresentados os resultados das variáveis analisadas.

Tabela 1. Média e desvio padrão das variáveis limnológicas do Córrego

Chumbeadinha, Ourinhos/SP, no período de setembro de 2009 a de abril de 2010.

\begin{tabular}{ccccccccc}
\hline Parâmetro & Média & CV\% & DP & Min & $1^{\circ} \mathrm{Q}$ & $2^{\circ} \mathrm{Q}$ & $3^{\circ} \mathrm{Q}$ & Max \\
\hline Temperatura & 25,27 & 8,54 & 2,16 & 21,4 & 23,72 & 24,9 & 27 & 31 \\
Oxigênio Dissol. & 5,63 & 34,1 & 1,92 & 1,86 & 4,36 & 5,61 & 7,07 & 12,53 \\
Cond. elétrica & 113,56 & 13,48 & 15,31 & 83,7 & 103,38 & 111,1 & 121,2 & 152,66 \\
pH & 6,8 & 10 & 0,68 & 5,23 & 6,48 & 6,99 & 7,22 & 8,43 \\
Transp. da água & 65,07 & 26,6 & 17,31 & 26 & 53,74 & 67,66 & 74,32 & 94 \\
\hline
\end{tabular}

A nascente onde se localiza o ponto 1 manifesta-se perene, segundo Valente e Gomes (2005), já que os fluxos da sua vazão são alterados de acordo com as estações 
vigentes, aumentando na primavera e verão, e diminuindo no outono e inverno.

A vazão da nascente teve um valor médio de 542,99 L/mim. O valor mais elevado da vazão foi de $666,31 \mathrm{~L} / \mathrm{mim}$ e o menor valor de 441,46 L/mim, uma diferença de quase 200 L/mim. A variação sazonal do regime pluviométrico não teve uma influência direta na vazão da nascente, demonstrando que provavelmente o recurso subterrâneo não é afetado por recarga direta da chuva, provavelmente as águas do Chumbeadinha vêm de reservas subterrâneas que se encontram nas rochas subsuperficiais, assim podendo explicar a constância na vazão.

Os valores apresentados na média de todos os pontos de coleta, em geral foram próximos aos valores preconizados pela Resolução CONAMA 357/05, sendo a média dos resultados aparenta-se de um córrego de qualidade razoável. No entanto esses valores podem ser mais acentuados nos quatro diferentes pontos, sendo assim, a seguir serão apresentados os resultados dos pontos específicos separadamente.

Tabela 2. Média e desvio padrão das variáveis limnológicas em cada ponto de amostragem do Córrego Chumbeadinha, Ourinhos/SP, no período de setembro de 2009 a de abril de 2010 .

\begin{tabular}{lcccc}
\hline Parâmetros & $\begin{array}{c}\text { P1 } \\
\text { Nascente }\end{array}$ & $\begin{array}{c}\text { P2 } \\
\text { Lago 1 }\end{array}$ & $\begin{array}{c}\text { P3 } \\
\text { Lago 2 }\end{array}$ & Ladrão \\
\hline Temperatura $\left({ }^{\circ} \mathrm{C}\right)$ & $24,28 \pm 0,98$ & $25,71 \pm 2,14$ & $26,29 \pm 2,53$ & $24,78 \pm 2,24$ \\
Oxigênio Dissolvido $(\mathrm{mg} / \mathrm{L})$ & $4,92 \pm 1,16$ & $4,45 \pm 2,63$ & $6,23 \pm 1,64$ & $6,93 \pm 0,90$ \\
Condutividade Elétrica $(\mu \mathrm{S} / \mathrm{cm})$ & $120,96 \pm 16,43$ & $107,01 \pm 15,36$ & $111,13 \pm 12,88$ & $115,01 \pm 13,69$ \\
$\mathrm{pH}$ & $5,78 \pm 0,26$ & $6,98 \pm 0,19$ & $7,41 \pm 0,39$ & $6,96 \pm 0,36$ \\
Vazão & $542,99 \pm 57,28$ & - & - & - \\
Transparência $(\mathrm{m})$ & - & $0,57 \pm 17,02$ & $0,73 \pm 14,24$ & - \\
\hline
\end{tabular}

As variáveis mensuradas variaram pouco, com exceção da concentração de oxigênio dissolvido, pois segundo Gomes (2000) e Sipaúba-Tavares (1994) em águas naturais, a concentração do oxigênio está constantemente mudando devido a processos biológicos, físicos e químicos, além de estar ligada ao processo de fotossíntese e respiração/decomposição. A quantidade de oxigênio pode ser afetada por dois fatores principais: temperatura e condutividade. A diminuição na temperatura acarreta em 


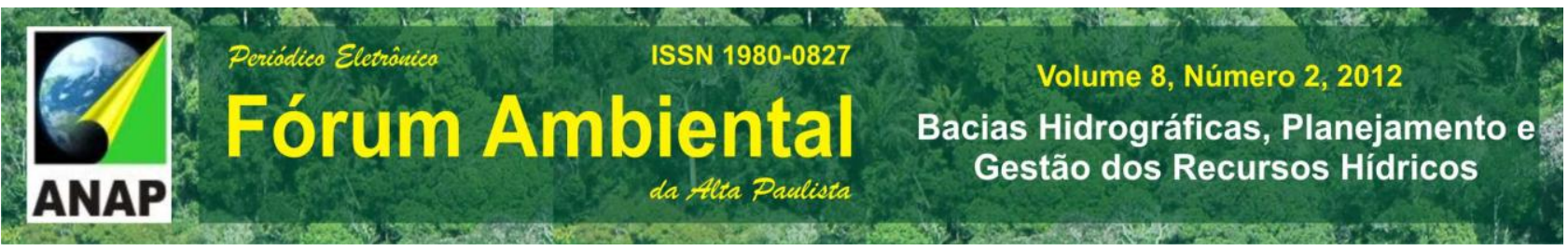

aumento na solubilidade do oxigênio, enquanto que valores elevados de condutividade acarretam uma diminuição da solubilidade do oxigênio na água. Segundo SipaúbaTavares e Moreno (1994), quando as concentrações de O.D. são muito baixas, os animais aquáticos podem ficar estressados e consequentemente ocasionando a diminuição de sua sobrevivência e produção.

Com relação ao $\mathrm{pH}$, somente na nascente a média foi abaixo, porém próxima do que a Resolução CONAMA 357/05 preconiza como valores adequados, em ambientes aquáticos, que são entre 6 a 9. De acordo com Esteves (1998) as comunidades vegetais, animais e o meio aquático possuem estreita interdependência com o pH, sendo uma das variáveis mais difíceis de se interpretar, devido, principalmente, ao grande número de fatores que podem influenciá-lo, como por exemplo, a geologia local, a decomposição da matéria orgânica e processos biológicos, que contribuem para o aumento ou a diminuição dessa variável em ambientes aquáticos.

A condutividade elétrica nos pontos amostrados pôde ser considerada intermediária, denotando características mesotróficas, quando comparada com reservatórios considerados eutróficos, como o de Barra Bonita, SP, em que valores da condutividade chegaram a $291 \mu \mathrm{S} . \mathrm{cm}^{-1}$ (Santos-Wisnieswski, 1998).

Os valores da transparência da água apresentaram um desvio padrão relativamente alto. Fato que pode estar relacionado baixos valores como encontrados (26 $\mathrm{cm})$ em águas mais turvas e valores mais altos $(93 \mathrm{~cm})$ representam águas mais cristalinas, indicando uma maior zona eufótica, com consequência uma maior taxa fotossintética, e provavelmente os maiores valores da concentração de O.D. no ponto, quando comparado com o ponto 2 .

A turbidez da água pode variar conforme a ocorrência de chuvas e descarga de sedimentos no lago, e a existência de uma fábrica de tijolos ao lado da nascente, pode depositar material ao longo do curso hídrico, contribuindo com a maior deposição de materiais. $O$ depósito de sedimento é um fator visivelmente frequente no lago 1 , já que foi possível observar bancos de areia nas bordas do lago, bem como a coloração barrenta, denotando uma quantia considerável de sólidos em suspensão.

A zona eufótica corresponde à porção iluminada da coluna d'água que pode variar de poucos centímetros até dezenas de metros, onde se encontra a maioria dos 
organismos produtores em ecossistemas aquáticos. A extensão desta pode ser afetada pela entrada de material alóctone, com a qual mantém uma relação inversa, pois quanto maior a entrada de material, menor será a penetração de luz (Esteves, 1998).

Os resultados obtidos para o índice de estado trófico médio no córrego da Chumbeadinha estão apresentados na Figura 2. Durante o período amostrado os pontos 2 e 3 foram classificados, de acordo com o índice de estado trófico médio, como eutróficos. Para os pontos P1 (nascente) e P4 (ladrão) não foi calculado o índice de estado trófico, pela dificuldade em aferir o disco de Secchi.

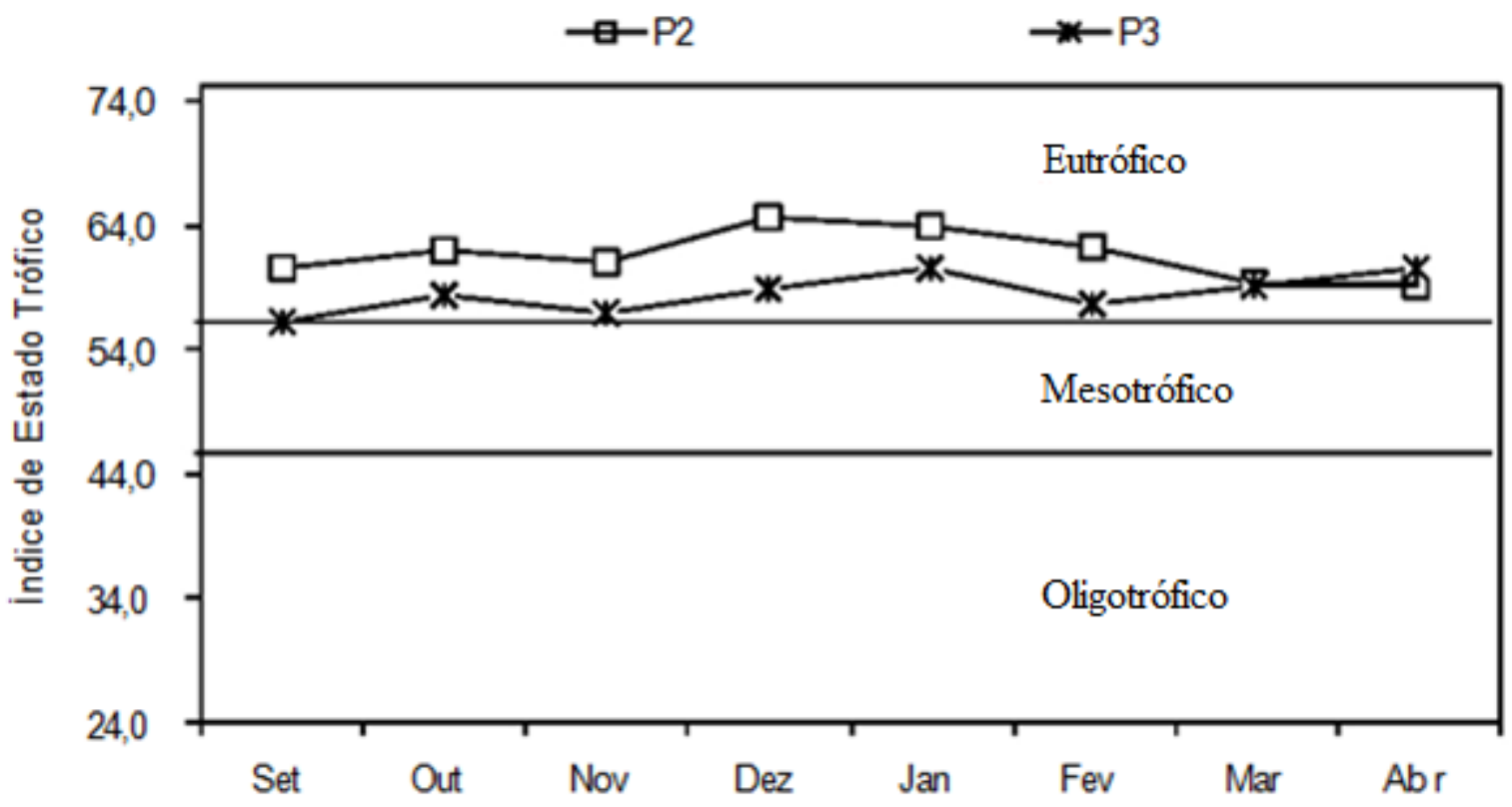

Figura 2. Variação dos valores do Índice de Estado trófico (IET) para a coluna d'água dos pontos amostrados (P2, P3) no córrego Chumbadinha, no município de Ourinhos/SP, no período de setembro de 2009 a abril de 2010 .

Os pontos P2 e P3 foram classificados como eutróficos, provavelmente por sofrerem ações antrópicas no seu entorno, juntamente com o lançamento de esgotos domésticos e/ou industriais que promovem a entrada de nutrientes, alterando o equilíbrio ecológico do ecossistema (Rull Del Aguila, 2001). Os valores do IET elucidam que a qualidade da água não está adequada, pois a ocorrência de matéria orgânica aumenta a DBO e pode prejudicar a vida das comunidades aquáticas do córrego Chumbeadinha. 
Em relação aos testes de presença ou ausência de coliformes Totais e E.coli, pôde ser observada a presença de coliformes fecais em todas as amostragens. Assim as bactérias termotolerantes são exclusivas de animais de sangue quente, sendo assim existem muitas espécies que podem contaminar os cursos hídricos, porém os maiores contaminadores são os seres humanos com as ligações clandestinas das redes de esgoto, que acabam interferindo diretamente na dinâmica das águas e alterando a sua potabilidade e consequentemente sua qualidade.

\section{CONCLUSÕES}

O gerenciamento dos recursos hídricos é importante para a manutenção da qualidade e da quantidade de água potável no planeta e através do monitoramento constante, fundamentado por políticas públicas, são fundamentais para que os corpos hídricos mantenham seu potencial máximo. Visto que o presente estudo demonstrou que - Córrego Chumbeadinha nasce com uma qualidade boa, e sofre forte pressão pela expansão urbana. Sua nascente é cercada por bairros e empreendimentos que prejudicando sua qualidade, além do despejo de sedimentos aliado a falta de mata ciliar próxima a nascente, comprometendo a qualidade dos recursos hídricos do município de Ourinhos-SP.

\section{REFERÊNCIAS}

APHA/AWWA/WEF. Standard Methods for the Examination of Water and Wastewater, 20. ed. Washington: APHA, 1998.

CALLISTO, M.; GONÇALVES, J.F. \& MORENO, P. 2005. Invertebrados Aquáticos como Bioindicadores. In: Goulart, E.M.A. (Eds). Navegando o Rio das Velhas das Minas aos Gerais, 555-567.

COLWELL, R.R. Bacterial and viruses-indicator of environmental changes occurring estuaries. Environ. Int.,1:223-31,1978.

CONAMA. Resoluções do CONAMA: resoluções vigentes publicadas entre julho de 1984 a junho de 2010. Brasília: CONAMA, 2010. Disponível em: $<$ http://www.mma.gov.br/port/conama/legiano.cfm?codlegitipo=3>. Acesso em: 2 jun. 
2010.

ESTEVES, F. A. Fundamentos de Limnologia. 2a ed. Rio de Janeiro: Interciência Ltda, 1998. 575p.

GOMES, P. F. Curso de estatística experimental. 14.ed. Piracicaba: Degaspari, 2000. $477 \mathrm{p}$.

INSTITUTO DE PESQUISAS TECNOLÓGICAS DO ESTADO DE SÃO PAULO. Mapa geológico do estado de São Paulo. São Paulo, 1981. Escala:500.000.

MARGALEF, R. Limnologia. Omega, 1983, 1010p.

MORAES, A. J. Manual para avaliação da qualidade da água - 1. São Carlos: Rima, 2004.

RULL DEL AGUILLA, L. M. Gradiente trófico no rio Sapucaí (Reservatório de Furnas MG): relação com a distribuição do zooplâncton e os usos do solo. 2001, 82f. Dissertação (Mestrado em Ecologia, Conservação e Manejo da Vida Silvestre) - Instituto de Ciências Biológicas, Universidade Federal de Minas Gerais, Belo Horizonte. 2001.

SANTOS-WISNIEWSKI, M. J. Distribuição espacial e produção secundária da comunidade zooplanctônica do Reservatório de Barra Bonita - SP. 1998. Tese (Doutorado em Ciências) - Centro de Ciências Biológicas e da Saúde, Universidade Federal de São Carlos, São Carlos, 1998.

SIPAÚBA-TAVARES, L. H; MORENO, S. Q. Variação dos parâmetros limnológicos em um viveiro de piscicultura nos períodos de seca e chuva. Rev. UNIMAR, v. 16, n. 4, p. 229242, 1994.

SIPAÚBA-TAVARES, L. H; MORENO, S. Q. Variação dos parâmetros limnológicos em um viveiro de piscicultura nos períodos de seca e chuva. Rev. UNIMAR, v. 16, n. 4, p. 229242, 1994.

STRAHLER AN. Quantitative analysis of watershed geomorphology. Trans Am Geophys Union n.38, p.913-920, 1957.

TOLEDO, A. P; TALARICO, M; CHINEZ, S. J; AGUDO, E. G. A aplicação de modelos simplificados para avaliação do processo da eutrofização em lagos e reservatórios tropicais. In: CONGRESSO BRASILEIRO DE ENGENHARIA SANITÁRIA E AMBIENTAL. 1983 Camboriú. Anais... Camboriú, Congresso Brasileiro de Engenharia Sanitária e Ambiental, 1983. p. 1-34.

TUCCI, C. E. M. (Org.) Hidrologia: Ciência e Aplicação. Porto Alegre: Ed. Da Universidade: ARBH: EDUSP, 2007. 
UNITED NATIONS ENVIRONMENT PROGRAMME GLOBAL ENVIRONMENT MONITORING SYSTEM/WATER PROGRAMME. Water quality: for ecosystem and human health, UNEP GEMS/Water Programme, 2006.

VALENTE, O. F; GOMES, M. A. Conservação de nascentes: hidrologia e manejo de bacias hidrográficas de cabeceiras. Viçosa-MG: Aprenda Fácil Editora, 2005. 